Revista Eletrônica de Estudos Integrados em Discurso e Argumentação ISSN 2237-6984

\title{
Resenha de "Retórica e discurso - fronteiras e interfaces: das origens aos desdobramentos atuais. homenagem à Professora Lineide do Lago Salvador Mosca", de Hubert \& Bento (Org.).
}

\section{Maria Helena Cruz Pistori}

Doutora em Filologia e Linguística Portuguesa pela Universidade de São Paulo (USP), Brasil. mhcpist@uol.com.br

Resumo: O texto apresenta a obra recém-publicada Retórica e discurso - fronteiras e interfaces: das origens aos desdobramentos atuais. Homenagem à professora Lineide do Lago Salvador Mosca, organizada por Elizabete Enz Hubert e Emilson José Bento. Inicialmente a resenha contextualiza a obra e seu surgimento, destacando aspectos da trajetória acadêmica da homenageada e do grupo fundado por ela (GERAR). A seguir, indica brevemente conteúdos que o leitor encontrará nas três partes em que a obra foi dividida.

Palavras-chave: Retórica. Discurso. Homenagem

\begin{abstract}
The text presents the newly-published work Retórica e discurso - fronteiras e interfaces: das origens aos desdobramentos atuais. Homenagem à professora Lineide do Lago Salvador Mosca, organized by Elizabete Enz Hubert and Emilson José Bento. At first, the review contextualizes the work and its emergence, highlighting aspects of the academic trajectory of the honoree and the group founded by her (GERAR). It then briefly indicates content that the reader will find in the three parts in which the work was divided.
\end{abstract}

Keywords: Rhetoric. Discourse. Homage. 
A retórica é útil, porque o verdadeiro e o justo são, por natureza, melhores que seus contrários. Donde se segue que, se as decisões não forem proferidas como convém, o verdadeiro e o justo serão necessariamente sacrificados: resultado este digno de censura (1355a).

Aristóteles

Viver significa participar do diálogo: interrogar, ouvir, responder, concordar, etc. Nesse diálogo o homem participa inteiro e com toda a vida: com os olhos, os lábios, as mãos, a alma, o espírito, todo o corpo, os atos. Aplica-se totalmente na palavra, e essa palavra entra no tecido dialógico da vida humana, no simpósio universal Mikhail Bakhtin

Antes de tudo, é preciso contextualizar esta obra. Já é um truísmo, na área dos estudos da linguagem, a afirmação de que o renascimento da retórica ocorre em 1958, com os trabalhos de Chaïm Perelman e Lucie Olbrechts-Tyteca - Tratado da argumentação: a nova retórica, e Stephen Toulmin - Os usos do argumento. A essas duas obras fundamentais, que retomaram, reavaliaram e propuseram novas leituras das retóricas grega e romana, seguiram-se vários outros modos de revitalização da antiga disciplina, bem registrados em Velhas e novas retóricas: convergências e desdobramentos, de Lineide do Lago Salvador Mosca, primeiro dos artigos de Retóricas de ontem e de hoje, obra também organizada por ela, cuja primeira edição é de 1997 (2001, p. 17-54).

No entanto, o interesse de Mosca pela questão da persuasão discursiva, antecede essa publicação. Consultando seu CV Lattes, constatamos que ela hoje professora livre-docente no Departamento de Letras Clássicas e Vernáculas da Faculdade de Filosofia, Letras e Ciências Humanas da Universidade de São Paulo, oferece a disciplina de "Retórica e argumentação”, na graduação, desde 1988; e, na pós-graduação, desde 1992. Ao longo de toda sua carreira investiu nos estudos e aprofundamento do tema, tanto no Brasil, como na França, Bélgica, Alemanha e Estados Unidos, ora como pesquisadora, ora como professora-visitante de diferentes universidades.

Assim, é o louvor e o reconhecimento por um trabalho persistente, profícuo e amplo que motiva a publicação de Retórica e discurso - fronteiras e 
interfaces: das origens aos desdobramentos atuais. Homenagem à professora Lineide do Lago Salvador Mosca, pela editora Pontes (2019). A obra foi organizada por Elizabete Enz Hubert e Emilson José Bento, ambos orientados por ela em seus doutorados na Universidade de São Paulo.

Em seu lançamento na Livraria Martins Fontes, muitos alegavam, de modo bem-humorado, ser a obra a nova "Bíblia" da argumentação, sobretudo por suas 781 páginas. Ainda que isso possa soar exagerado, na realidade, os organizadores da obra coletiva reuniram ali 29 textos de autores que, de uma ou outra forma, estiveram ligados a Lineide Mosca ao longo desses anos todos. E a competente Apresentação, assinada por Hubert e Bento, dá ao leitor uma visão não apenas das justificativas da publicação, mas também de todos os textos que ali encontraremos.

Nos entusiasmados primeiros parágrafos, os organizadores já definem a dupla homenagem consubstanciada na obra: à mestra e ao Grupo de Pesquisa GERAR - Grupo de Estudos de Retórica e Argumentação que coordena. Foi fundado em 1994, no momento em que a professora desenvolvia o projeto “Retórica e argumentação. Exame de procedimentos discursivos". Dizem eles: "Homenagem é reconhecimento! Quem homenageia reconhece na dedicação perseverante de toda uma vida dons maduros de saber, que o tempo e a persistência tornam sabedoria, que permanecem e edificam outras vidas" (HUBERT; BENTO, 2019, p. 9). Desse modo, a produção textual reunida na obra é, sem dúvida, fruto do esforço e dedicação da mestra. É também dela! Sobre o dinâmico funcionamento do GERAR, que completa vinte e cinco anos de fundação, suficiente consultar seu site, no portal da USP http://gerar.fflch.usp. br/quem-somos. E, se pensarmos mais amplamente em frutos de seu trabalho, devemos ainda considerar o periódico EID\&A, cujos editores fundadores, Eduardo Lopes Piris \& Moisés Olímpio-Ferreira, e também Isabel Cristina Michelan de Azevedo, foram orientados pela professora Lineide.

A capa do livro oferece ao leitor uma ideia de seu conteúdo: são discursos, estudos sobre discursos. As duas imagens retratam assembleias, lócus dos discursos do gênero deliberativo, muito semelhantes: à esquerda, um anfiteatro antigo, em que orador e plateia debatem, todos em túnicas brancas, lembrando-nos o senado nos tempos de Roma. À direita, o espaço é 
contemporâneo: o anfiteatro, também em semicírculo, apresenta uma tela por detrás da tribuna, assentos à frente e um balcão ao redor da plateia para observadores; parece ser o senado brasileiro. Como sabemos, a esfera política, desde a democracia grega, é um campo em que a retórica sempre esteve presente. E a capa atesta esse fato. "A instância da enunciação e de sua cenarização permite acessar o sócio-histórico” (HUBERT; BENTO, 2019, p. 11), lembram os organizadores. E acrescentam: "Os estudos retóricoargumentativos situam-se em um quadro maior, o dos estudos discursivos, o que parece ser uma das grandes contribuições de nossa homenageada" (HUBERT; BENTO, 2019, p. 12).

O livro está organizado em três partes. Tanto a primeira quanto a segunda apresentam artigos predominantemente teóricos. Na terceira, ao lado dos aspectos teóricos, diferentes objetos são analisados, em uma abordagem multidisciplinar. A identificação e filiação acadêmica dos autores encontram-se em notas de rodapé, mas nem sempre de modo mais completo, o que, provavelmente, se deve às informações fornecidas por eles mesmos.

$\mathrm{Na}$ primeira parte, intitulada "Percorrendo a história da retórica: dos gregos e romanos aos nossos dias", encontram-se sete artigos. Todos eles tratam da retórica no mundo antigo, a retórica greco-romana, numa ordem cronológica que chega à atualidade. No artigo de José Rodrigues Seabra Filho (USP) - Cícero e a retórica greco-romana, o destaque é a figura de Marco Túlio Cícero, grande mestre da retórica latina. A república consular romana do período republicano, do séc. $\mathrm{V}$ aC até praticamente a época de Cícero, cuja carreira se inicia em 86 aC, é o pano de fundo para seus discursos, muitos deles parcialmente recuperados no texto. $O$ artigo seguinte - Retórica e exegese na pregação crista, Emilson José Bento - que teve seu doutorado orientado por Mosca, ao analisar a retórica de Santo Agostinho, aponta modos como as pregações dos primeiros cristãos se apropriaram da cultura greco-romana; e Lênia Márcia Mongelli (USP), em A retórica e os prólogos dos livros de cavalarias, trata dos textos literários medievais, ressaltando engenhosidades retóricas dos romances de cavalaria a partir do século XI. Segue-se um estudo sobre a lírica galego-portuguesa - Recursos retóricos na lírica galego-portuguesa: a litotes na "cantiga da guarvaia”, de Yara Frateschi Vieira (UNICAMP), levantando características próprias da lírica desenvolvida 
pelos trovadores e detendo-se sobre o uso da litotes na Cantiga da Ribeirinha ou Cantiga da Guarvaia, do trovador Pai Soares de Taveirôs.

Chegando à Idade Moderna, ainda nesta primeira parte, o estudo de Elaine C. Sartorellli (USP) a respeito de Erasmo de Rotterdam - A retórica na Idade Moderna: Erasmo de Rotterdam - busca observar sua importância no estabelecimento de conceitos retóricos importantes no Renascimento. E Moisés Olímpio Ferreira (IFSP), também ex-orientando de Lineide Mosca, em [Nova] retórica e argumentação: a negociação de um ponto de vista - aborda desdobramentos da retórica para além daquela "retórica restrita" apontada por Gérard Genette no texto publicado em Communications, 16, de 1970, pela École Pratique des Hautes Études - Centre d'Études des Communications de Masse (p. 158-171). Fechando essa primeira parte, o artigo de Débora Massmann (UNIVÁS-MG) - Argumentação: memória de sentidos e rupturas propõe-se a descrever e analisar o próprio sentido da palavra "argumentação", buscando delinear a história do conceito a partir de meados do séc. $X X$.

A segunda parte - "Desafios e perspectivas atuais para os estudos retórico-argumentativos", inicia-se com uma entrevista da professora Lineide ao pesquisador português Rui Alexandre Grácio, filósofo e doutor em Ciências da Comunicação e Filosofia (Universidade do Minho), com ênfase na área da Retórica, Argumentação e Análise do Discurso. Grande conhecedor da retórica em sua interface com a filosofia, a entrevista oferece ao leitor tópicos variados para reflexão, de questões culturais a educacionais e sobre o próprio desenvolvimento dos estudos retóricos atuais. Aprofundando o conhecimento dos estudos que têm desenvolvido, mais adiante, ainda nessa segunda parte, o artigo de Grácio - Compreensão, argumentação e retórica, permite-nos entrever a interface desses conceitos com a hermenêutica. É após a entrevista, no entanto, que encontramos o artigo Novos tempos, novos paradigmas: os desafios dos estudos retóricos na modernidade, de Lineide Mosca, no qual a autora apresenta o que poderia ser compreendido como uma atualização do artigo de 1997, citado anteriormente, colocando o leitor diante de um amplo panorama do que se entende por estudos retóricos na atualidade. Os dois últimos artigos dessa parte também mostram aspectos contemporâneos dos estudos retóricos: Ivo Dittrich (UNIOESTE), em A plasticidade do sentidos e seu uso estratégico na argumentação, trata da 
adequação dos sentidos em diferentes textos, examinando especialmente as "noções confusas", teórica e metodologicamente, no todo da obra de Chaïm Perelman, e ainda suas relações com as metáforas. Encerrando esta parte da obra, um estudo sobre a retórica - "terceiro ramo da semiótica", segundo Charles S. Peirce - A retórica segundo Peirce, redigido por Vinícius Romanini (ECA-USP).

Como se pode comprovar, apenas essas duas primeiras partes teóricas já definiriam a importância da publicação, dando ao leitor muito material para reflexões profundas. Mas a terceira parte nos mostra como aqueles conceitos teóricos podem ser mobilizados na compreensão de diferentes aspectos e objetos de nossa sociedade. Seu título "Retórica e argumentação: abordagens multidisciplinares em torno de múltiplos objetos" aponta justamente para a interdisciplinaridade dos estudos retóricos desenvolvidos sob os auspícios da professora Lineide Mosca. De modo geral, ousamos afirmar que, aproximando-se do que seria uma abordagem bakhtiniana dos discursos, as análises tomam os objetos em sua integridade concreta e viva, buscando-lhes o sentido na interação do verbal com o extraverbal, isto é, descrevem-se e analisam-se discursos situados espacial e temporalmente, com um autor e um destinatário (Cf. Bakhtin, 2008, p. 207; Volóchinov, 2017, p. 220, entre outros). Temos nessa parte, então, trabalhos que se debruçam sobre o discurso jurídico, o discurso religioso, o discurso literário, o discurso midiático, o discurso musical e ainda o discurso educacional.

Como se vê, a gama é bastante ampla e permite ao leitor entrever possiblidades múltiplas de diálogo com diferentes temas importantes de nossa sociedade. Como afirmam os organizadores:

Nesta rota, cada um poderá decidir onde deseja parar, que lugares deseja visitar, sempre conforme os seus interesses e opções teóricas. No conjunto, a obra reflete a intensidade e qualidade dos trabalhos realizados em torno do GERAR no decorrer dos últimos anos mostrando que o grupo é uma verdadeira comunidade de espíritos em contínuo diálogo sobre a retoricidade constitutiva da vida social e da cultura (HUBERT; BENTO, 2019, p. 29).

Não há como fugir: a resenha é um discurso epidítico, aquele que serve à crítica ou ao elogio de homens e feitos. Neste caso, os louvores à realização da obra são muitos, mesmo que, nos artigos, se possam configurar níveis de qualidade e aprofundamento diversos. Mas, enfim, a publicação é uma 
abertura para o diálogo e sua leitura deve suscitar tanto respostas responsáveis de leitores e autores, como promover a discussão de objetos teóricos e a análise de práticas argumentativas em nossa sociedade.

\section{Referências}

ARISTÓTELES. Retórica. Prefácio e introdução de Manuel Alexandre Júnior. Tradução: e notas de Manuel Alexandre Júnior, Paulo Farmhouse Alberto e Abel do Nascimento Pena. 3.ed. Lisboa: Imprensa Nacional - Casa da Moeda, 2006.

BAKHTIN, Mikhail. Problemas da poética de Dostoiévski. 4.ed. Tradução: Paulo Bezerra. Rio de Janeiro: Forense Universitária, 2008.

BAKHTIN, Mikhail. Adendo 2. In: . Problemas da poética de Dostoiévski. 4.ed. Tradução: Paulo Bezerra. Rio de Janeiro: Forense Universitária, 2008.

GENETTE, Gérard. La rhétorique restreinte. Communications, Paris, n. 16, p. 158-171, 1970.

MOSCA Lineide Salvador. Velhas e novas retóricas: convergências e desdobramentos. In:___ (Org.). Retóricas de ontem e de hoje. São Paulo: Humanitas, 2001.

PERELMAN, Chaïm; OLBRECHTS-TYTECA, Lucie. Tratado da argumentação. A nova retórica. Tradução: Maria Ermantina Galvão G. Pereira. São Paulo: Martins Fontes, 1996.

TOULMIN, Stephen E. Os usos do argumento. Tradução: Reinaldo Guarany. São Paulo: Martins Fontes, 2006.

VOLÓSHINOV, Valentin (Círculo de Bakhtin). Marxismo e filosofia da linguagem. Problemas fundamentais do método sociológico na ciência da linguagem. Tradução, notas e glossário: Sheila Grillo e Ekaterina Vólkova Américo. Ensaio introdutório: Sheila Grillo. São Paulo: Editora 34, 2017.

\section{Forma de citação sugerida}

PISTORI, Maria Helena Cruz. Resenha de "Retórica e discurso - fronteiras e interfaces: das origens aos desdobramentos atuais. homenagem à Professora Lineide do Lago Salvador Mosca", de Hubert \& Bento (Org.). EID\&A - Revista Eletrônica de Estudos Integrados em Discurso e Argumentação, Ilhéus, n. 20, v. 1, p. 286-292, 2020. DOI 10.17648/eidea-20-v1-2652. 